\title{
APPROACHES TO STUDYING ACROSS CULTURALLY CONTRASTING GROUPS: IMPLICATIONS FOR SECURITY EDUCATION
}

\author{
Dorota DOMALEWSKA, PhD \\ d.domalewska@akademia.mil.pl \\ War Studies University
}

\begin{abstract}
The problem of increased migration and integration of migrant children in schools has become a serious challenge for Security Education, especially the question of how to teach increasingly varied groups of students and whether students that come from culturally contrasting groups differ in their preferred learning style. This study sets out to analyse how students of various cultural backgrounds approach learning tasks, which is of utmost importance nowadays given that modern schools face the challenge of educating culturally diverse students. To this end, the Approaches and Study Skills Inventory for Students (ASSIST) was administered to 450 Thai students in a Thai university. The correlation between the learning approaches and individual differences (age, GPA and major) was assessed. Then, the results of the study were compared with the results of similar studies carried out in different cultures. The results show that the students scoring higher on the deep approach have the highest academic performance, whereas the students who approach the learning material strategically achieve the lowest learning outcomes. Furthermore, the Thai students did not differ significantly from their western peers (Norwegian, Egyptian, Portuguese and British); however, their results differed from the students from China, who generally scored lower on all subscales of the ASSIST scores. Thus, the findings of the study prove that the integration of migrant children can be highly successful because both migrant and host society students adopt similar approaches and strategies that strive for academic excellence.
\end{abstract}

Key words: multicultural education, learning style, Approaches and Study Skills Inventory for Students, ASSIST, approaches to studying, Security Education 


\section{Introduction}

Security Education is security-awareness training whose aim is to show students how to ensure safety in their local environment as well as to train them how to act in the event of a threat or a critical situation. Dangers occurring during peace time range from political, social, economic to environmental threats and the role of schools is not only to empower students to be able to guarantee security in each of the fields, but also to adopt a responsible attitude and express readiness to solve challenges to security (cf. Urych 2016; Urych 2018; Pieczywok 2012). Migration is one of the threats to societal security since the increasing flow of immigrants affects the social structure of the host society. Similarly, a growing number of migrant children studying in Polish schools influence the structure of student groups, which raises a question as to their ability to excel academically if they study in such a diverse group.

Academic performance is enhanced through individualised instruction and effective learning strategies. Learning according to one's cognitive preferences determines student achievement; therefore, identifying students' approaches to learning will support both learning and instruction. Raising students' awareness of their learning styles, as well as recognising their strengths and weaknesses as learners, can help them to become more successful learners. A number of students perform poorly because they have not developed effective learning strategies and are not able to deal with the stress of having to study a large amount of information under time pressure. Moreover, the instruction they get in the classroom fails to match their individual learning preferences. Research studies prove that learning according to one's cognitive preferences helps to produce better learning outcomes; therefore, identifying students' learning styles supports both learning and instruction. As students differ in their approaches to learning, interests, cognitive preferences, and ways of responding to instruction, the teacher that offers differentiated instruction facilitates students' growth (Lauria 2010).

Although learning styles have been researched widely, there is a paucity of research on learning styles across culturally contrasting groups. Therefore, this study sets out to analyse how students of various cultural backgrounds approach learning tasks, which is of utmost importance nowadays given that modern schools face the challenge of educating culturally diverse students. Classrooms nowadays consist 
of students that come not only from diverse social and ethnic groups but also from countries where instruction is delivered according to different principles. Thus, the schooling experience and study habits of learners varies. By giving an in-depth analysis of the students' learning preferences, the results of this study can be used to adjust instruction offered to students in order to improve their learning.

The study aims to answer the following research questions: (1) to investigate the learning styles of undergraduate students at a Thai University; (2) to analyse whether the learning styles are impacted by various characteristics, including gender, GPA, and major; (3) to determine whether learning styles are culturespecific. The answers to the above questions provide a solution to the problem of teaching culturally contrasting students. The article first discusses the effect of learning styles on students' academic performance. Next, the study is discussed and the results and conclusions are revealed.

\section{Learning Styles}

Learning outcomes are determined by a number of specific cognitive, affective, physiological, and sociological factors. Learning style, which is one of the factors that affects the learning process, has been researched since the 1970s, when researchers started extensively documenting learning-style preferences, study strategies and their effect on academic performance.

Learning style can be defined as the ways in which students begin to concentrate on, process, internalise, and remember new and difficult academic information (Dunn and Dunn 1993; Dunn and Griggs 2000). A large body of research proves the correlation between higher educational achievement and approaching the learning task according to one's cognitive preferences (Wang et al. 2006; Evans and Waring 2009). Rochford (2004) compared a traditional classroom approach and the learning-style based methodology of a remedial writing course. The results of her study show instruction that matches the students' preferred learning styles greatly affects student achievement, curiosity, grade-point-averages, and retention rates. Minotti (2005) focused on assigning students homework matching their approach to learning. The results showed that the students who completed individualised 
learning-style based assignments demonstrate significant achievement in reading, mathematics, science, and social studies. However, the teacher's educational practice is not the sole factor that affects student performance. Academic outcome is also correlated with individual learner differences, such as the students' personality, ability, motivation, and attitude.

Over 70 models of learning styles have been developed; they derive from competing ideas about learning and contrastive theories in the field of psychology, sociology, education, and policy studies; however, it needs to be remembered that a large number of learners use a combination of learning styles. Learning styles exist as a continuum rather than polar opposites. Furthermore, learning styles are valueneutral; there are no good or bad learning styles. However, students should have their learning strengths and weaknesses pointed out and they should develop their learning styles to become more empowered in their studies (Alikbarri and Qasemi 2012).

Noel Entwistle and his colleagues at Lancaster University and the University of Edinburgh have advanced a heuristic model of the teaching-learning process that investigates the complex interdependence between students' study methods, their approaches to learning, intellectual development, motivation, and academic achievement as well as the potential effects of instruction, course design, environment and evaluation on study goals and approaches to learning (Coffield et al 2004). According to Entwistle (2000), students tackle learning tasks differently because the specific intention they have towards learning varies, which in turn requires different learning processes and produces varied learning outcomes. Students who have developed the deep approach study to understand the concepts are actively engaged in learning, they relate ideas to previous knowledge and experience, look for underlying patterns and principles (a holist strategy), as well as use evidence and evaluate the logic of an argument (a serialist strategy). On the other hand, students who adopt the surface approach get involved in learning in order to just solve the learning problem see the course as unrelated bits of information, memorise facts, study without reflecting on the sense of new ideas and the value of the task. Next, some students take a strategic approach to learning, i.e. they study to receive the best grades, and devote considerable effort to learning, strive to create the right conditions for studying, gather useful instructional materials, and are aware of evaluation criteria. Finally, learners 
who develop an apathetic approach, which is the exact opposite of the strategic approach, fail at managing study time and effort effectively. Table 1 delineates the distinct differences between the strategies in terms of characteristics, learner intention, motivation, and strategy used.

\begin{tabular}{|l|l|l|l|l|}
\hline $\begin{array}{l}\text { Approach to } \\
\text { Learning }\end{array}$ & Characteristics & $\begin{array}{l}\text { Learner } \\
\text { Intention }\end{array}$ & $\begin{array}{l}\text { Learner } \\
\text { Motivation }\end{array}$ & $\begin{array}{l}\text { Learner Main } \\
\text { Strategy }\end{array}$ \\
\hline $\begin{array}{l}\text { Deep } \\
\text { Approach }\end{array}$ & $\begin{array}{l}\text { Looking for meaning } \\
\text { and personal interest, } \\
\text { enjoyment in studying, } \\
\text { relating new knowledge to } \\
\text { background knowledge, } \\
\text { drawing conclusions from } \\
\text { the evidence presented }\end{array}$ & $\begin{array}{l}\text { Understanding } \\
\text { the material }\end{array}$ & $\begin{array}{l}\text { Intrinsic } \\
\text { reeking meaning, } \\
\text { knowledge }\end{array}$ \\
\hline $\begin{array}{l}\text { Strategic } \\
\text { Approach }\end{array}$ & $\begin{array}{l}\text { Focusing on both the } \\
\text { interest in ideas and desire } \\
\text { to earn the best grades }\end{array}$ & $\begin{array}{l}\text { Academic } \\
\text { success }\end{array}$ & Extrinsic & $\begin{array}{l}\text { Selecting the optimal } \\
\text { strategy to maximise } \\
\text { academic success }\end{array}$ \\
\hline $\begin{array}{l}\text { Surface } \\
\text { Approach }\end{array}$ & $\begin{array}{l}\text { Rote learning, a lack of } \\
\text { purpose, fear of failure, } \\
\text { investing minimal personal } \\
\text { and involvement effort }\end{array}$ & $\begin{array}{l}\text { Reproducing } \\
\text { the material }\end{array}$ & Extrinsic & Memorisation \\
\hline
\end{tabular}

Table 1. Characteristics of Approaches to Learning (adapted from Gadelrab 2011)

Learning can be represented in the form of a continuum of growing awareness through a broader, integrative conception: first, conceptions of knowledge expand from dualism to relativism; second, conceptions of learning develop from reproducing to seeking meaning. Both conceptions of knowledge and conceptions of learning expand until learners stumble across a crucial threshold at which a significant qualitative shift in conception occurs, influencing the way in which students undertake their academic work. Crossing the threshold entails extended awareness of learning and recognition of personal evolution. This change coincides with a critical shift in learners' perception of the world, which is connected with a change in thinking, values and attitudes (Entwistle and McCune 2009).

Based on these conceptions, Entwistle developed a series of inventories that aim at investigating learning styles and strategies. First, Approaches to Studying Inventory (ASI) was developed in 1981 and then revised in 1995 in order to investigate individual differences in learning (Coffield et al 2004). The ASIST 
questionnaire (Approaches and Study Skills Inventory for Students) was devised in 1997. The new inventory contains improved conceptualisation of original scales, which is based on more recent research that has been summarised in Table 2 .

\begin{tabular}{|l|l|}
\hline Approach to learning & Components \\
\hline Deep & Seeking meaning \\
& Relating ideas \\
& Use of evidence \\
& Interest in ideas \\
\hline Strategic & Organised study \\
& Time management \\
& Alertness to assessment demands \\
& Achieving \\
& Monitoring effectiveness \\
\hline Surface & Lack of purpose \\
& Unrelated memorising \\
& Syllabus-boundness \\
& Fear of failure \\
\hline
\end{tabular}

\section{Table 2. Model of ASSIST components}

The deep approach to learning is the most effective approach as it is related to the disposition to understand for oneself, seeking meaning and relating ideas. This approach can be effectively developed in the classroom through exposure to authentic materials, real world problem solving, and relating learning tasks to personal life (Entwistle and McCune 2009). Furthermore, students need to see that the fundamental role of education is to develop thinking, a meaningful understanding for oneself and personal development.

\section{Learning strategies across culturally contrasting groups}

Research into learning strategies employed by students of different cultural backgrounds yields contrasting results. On the one hand, some studies show no culture-specific difference. Entwistle, Tait and McCune (2000) found learning strategies of British, Scottish and South African high school students were almost identical, even among students with low academic performance. On the other 
hand, a large body of research show a positive correlation between cultural background and learning styles. Apfelthaler et al (2005) carried out a cross-cultural analysis of approaches to learning among students in Germany, Austria, Thailand and Singapore who were found to adopt different attitudes towards learning. The differences are particularly significant among European and Asian students in the areas of teaching method and the role of teacher. Sun and Richardson (2012) investigated the correlation between the culture and study skills of British and Chinese postgraduate students majoring in Business. The subjects differed in the approach they use to studying: the British students scored higher on the strategic and deep approach than their Chinese peers. Holtbrügge and Mohr (2010) carried out a comprehensive study in which they analysed approaches to study of undergraduate students studying at universities in Germany, the USA, the UK, Ireland, the Netherlands, Spain, Poland, Russia, the United Arab Emirates, and China. The researchers found statistically significant differences in masculinity, individualism, study level, gender, and exchange student status among the students of different cultural backgrounds.

\section{Method}

The study adopts a quantitative correlational approach to examine individual differences in learning styles in higher education students. To collect data from the participants, the ASSIST (Approaches and Study Skills Inventory for Students) questionnaire was used. The data was analysed using SPSS (Statistical Package for the Social Sciences). Descriptive and inferential statistics such as frequency, standard deviation, skewness, kurtosis, correlations, Cronbach's Alpha and chisquare test were used to analyse the data.

\section{Research Objectives}

The research aims to investigate the preferred learning style of undergraduate students across culturally contrasting groups. The ultimate objectives of this paper are three-fold: to investigate the learning styles of undergraduate students 
at a Thai University; to analyse whether the learning styles are impacted by various characteristics, including gender, GPA, and major, and to determine whether learning styles are culture-specific. To meet the above-mentioned objectives, a survey analysis has been carried out.

\section{Participants}

This study was carried out on a sample of 450 undergraduate students majoring in Medical Technology (170 students), Tourism and Hospitality Industry (130 students) and English (150 students) from a university in Thailand. The subjects were selected on the basis of the convenience sampling method.

The survey instrument comprises two sections: basic demographic information, such as gender, GPA, major and the ASSIST questionnaire, which investigates individual differences in learning styles in students. The ASSIST questionnaire, which is widely used in research in the area of learning styles, has been developed at the Centre for Research on Learning and Instruction, University of Edinburgh, Scotland (Tait, Entwistle and McCune 1998). It is based on Marton and Saljo (1976) and Entwistle and Ramsden's (1983) studies on approaches to learning. Despite being useful in measuring students' cognitive preferences, the original ASSIST questionnaire consists of four sections and takes 10 - $15 \mathrm{~min}$ to administer, which is too long for this study as it also aims to analyse basic demographic information, such as sex, GPA, faculty, parents' education, type of high school attended as well as individual differences, such as personality (introversion vs. extraversion), and attitude towards teachers and teaching styles. For this reason, only the second section of the original ASSIST questionnaire was selected, namely Approaches to Study, which consists of 52 items, each comprising a statement with five options to measure levels of agreement / disagreement. For each item, the respondents were asked to select the option that best represents their preference. Only one option could be selected. The questionnaire has solid empirical evidence to support its construct and content validity.

The questionnaire, which was originally written in English, was translated into Thai so that the respondents could understand it properly. A qualified translator and proofreader were employed in the process of translating the questionnaire into Thai in order to ensure the quality of the translation. 
The ASSIST questionnaire responses were marked according to the accompanying scoring chart. The respondents' total score for each of the three main approaches was determined by adding the responses to the items in the subscale that contribute to each approach. The scores for the subscales were calculated to determine the students' approaches to learning: deep, strategic, and surface apathetic.

\section{Data Collection}

Data was collected from a convenience sample of undergraduate students at a Thai university. The questionnaire was administered during Semester 1/2016 in various class periods by the researcher in person. Prior to answering the survey questions, the students were informed about the purpose of the study. The respondents were asked to answer the questions with respect to their general approach to learning. Confidentiality of responses was ensured by maintaining the anonymity of the subjects. Participation in the study was voluntary. The time required to complete the questionnaire was approximately 5-10 minutes. Thai language version of the ASSIST questionnaire was administered.

\section{Data Analysis}

Descriptive and inferential statistical analyses were conducted using the Statistical Package for Social Sciences (SPSS). Frequency, standard deviation, skewness, kurtosis, Cronbach's alpha and chi-square test were the analyses used for the study. Frequency, standard deviation, skewness and kurtosis show the distribution of the students' answers. Cronbach's alpha measures the internal reliability of the research instrument. The chi-square test was carried out to derive conclusions about significant differences between dependent measures as a function of specific demographic variables including gender, GPA, and major. Finally, the results of the study were compared with the results of similar studies carried out in different cultures. 


\section{Results and Discussion}

Sample descriptive statistics for each scale were performed, including mean, standard deviation, skewness, and kurtosis (Table 3.).

\begin{tabular}{|l|l|l|l|l|l|}
\hline & Mean & SD & Skewness & Kurtosis & Cronbach's $\boldsymbol{\alpha}$ \\
\hline Deep approach & 15.59 & 0.73 & -0.39 & 0.27 & 0.78 \\
\hline seeking meaning & 16.31 & 0.68 & -0.37 & 0.14 & 0.51 \\
\hline relating ideas & 15.51 & 0.72 & -0.35 & 0.22 & 0.42 \\
\hline use of evidence & 15.84 & 0.67 & -0.13 & -0.25 & 0.42 \\
\hline interest in ideas & 14.69 & 0.80 & -0.37 & 0.22 & 0.59 \\
\hline Strategic approach & 15.71 & 0.74 & -0.47 & 0.30 & 0.83 \\
\hline organised study & 14.80 & 0.76 & -0.29 & 0.11 & 0.55 \\
\hline time management & 15.30 & 0.76 & -0.27 & 0.21 & 0.62 \\
\hline alertness to assessment demands & 16.14 & 0.69 & -0.39 & 0.14 & 0.45 \\
\hline achieving & 15.82 & 0.72 & -0.44 & 0.49 & 0.59 \\
\hline monitoring effectiveness & 16.48 & 0.67 & -0.43 & 0.33 & 0.42 \\
\hline Surface apathetic approach & 13.96 & 1.07 & -0.36 & -0.60 & 0.75 \\
\hline lack of purpose & 12.46 & 1.06 & -0.02 & -0.66 & 0.61 \\
\hline unrelated memorising & 13.60 & 1.08 & 0.37 & -0.56 & 0.41 \\
\hline syllabus-boundness & 13.84 & 0.98 & -0.31 & -0.43 & 0.3 \\
\hline fear of failure & 15.92 & 0.97 & -0.84 & 0.16 & 0.63 \\
\hline
\end{tabular}

Table 3. Descriptive statistics for ASSIST scales $(\mathrm{N}=350)$

The skewness and kurtosis observed are moderate; the values for skewness range from -1 to 0.5 , which is considered acceptable (Rubin 2012). The distribution of deep and strategic subscale scores is more symmetrical and negatively skewed with a relatively low standard deviation and mostly a positive degree of kurtosis. As for the surface apathetic subscale, the distribution of data is more varied but still within an absolute value of 1.0 , which gives evidence of normality.

Cronbach's alpha of the questionnaire has been determined in order to test its reliability. As Cronbach's alpha of a reliable questionnaire is higher than .70 (Field 2013), this questionnaire is reliable: Cronbach's alpha for each subscale varies from .75 to .83 (.78 for the Deep Approach, .83 for the Strategic Approach and .75 for the Surface Apathetic Approach). The alpha coefficient for individual sets making up each subscale is small (ranging from .30 to .62), which results from 
the fact that each subscale characteristic consists of only four items (Hof 2012). However, each subscale is composed of a large number of questions, which ensures reliability. Furthermore, Cronbach's alpha is comparable to other studies (Diseth 2001, Gadelrab 2011, Valadas, Goncalves and Faisca 2009, Sun and Richardson 2012) (see Table 4.).

\begin{tabular}{|l|l|l|l|l|l|l|}
\hline & $\begin{array}{l}\text { Thailand } \\
(\mathbf{N = 3 5 0})\end{array}$ & $\begin{array}{l}\text { Norway } \\
(\mathbf{N}=\mathbf{5 7 3})^{\mathbf{a}}\end{array}$ & $\begin{array}{l}\text { Egipt } \\
(\mathbf{N = 5 1 6})^{\mathbf{b}}\end{array}$ & $\begin{array}{l}\text { Portugal } \\
(\mathbf{N}=\mathbf{5 6 6})^{\mathbf{c}}\end{array}$ & $\begin{array}{l}\text { China } \\
(\mathbf{N = 2 0 7})^{\mathrm{d}}\end{array}$ & $\begin{array}{l}\text { UK } \\
(\mathbf{N}=\mathbf{1 3 4})^{\mathbf{d}}\end{array}$ \\
\hline Deep approach & 0.78 & 0.81 & - & 0.81 & - & - \\
\hline Seeking meaning & 0.51 & 0.49 & 0.82 & 0.51 & 0.74 & 0.76 \\
\hline Relating ideas & 0.42 & 0.62 & 0.85 & 0.54 & 0.74 & 0.77 \\
\hline Use of evidence & 0.42 & 0.49 & 0.8 & 0.59 & 0.71 & 0.75 \\
\hline Interest in ideas & 0.59 & 0.64 & 0.77 & 0.56 & 0.65 & 0.71 \\
\hline Strategic approach & 0.83 & 0.81 & - & 0.83 & - & - \\
\hline Organised study & 0.55 & 0.59 & 0.82 & 0.51 & 0.59 & 0.61 \\
\hline Time management & 0.62 & 0.72 & 0.83 & 0.65 & 0.68 & 0.74 \\
\hline $\begin{array}{l}\text { Alertness to assessment } \\
\text { demands }\end{array}$ & 0.45 & 0.41 & 0.79 & 0.4 & 0.5 & 0.58 \\
\hline Achieving & 0.59 & 0.66 & 0.86 & 0.67 & 0.61 & 0.75 \\
\hline Monitoring effectiveness & 0.42 & 0.51 & 0.82 & 0.58 & 0.63 & 0.72 \\
\hline $\begin{array}{l}\text { Surface apathetic } \\
\text { approach }\end{array}$ & 0.75 & 0.7 & - & & & \\
\hline Lack of purpose & 0.61 & 0.68 & 0.72 & 0.54 & 0.64 & 0.67 \\
\hline Unrelated memorising & 0.41 & 0.57 & 0.78 & 0.73 & 0.6 & 0.7 \\
\hline Syllabus boundness & 0.3 & 0.57 & 0.81 & 0.62 & 0.7 & 0.75 \\
\hline Fear of failure & 0.63 & 0.57 & 0.85 & 0.63 & 0.72 & 0.75 \\
\hline
\end{tabular}

${ }^{a}$ Diseth 2001

${ }^{\mathrm{b}}$ Gadelrab 2011

c Valadas, Goncalves, Faisca 2009

${ }^{\mathrm{d}}$ Sun and Richardson 2012

Table 4. Cronbach's Alpha coefficients

The chi-square test has been carried out in order to determine whether the variables are independent (Table 5.). Gender, GPA, major and learning styles are independent of each other because the critical value of chi-square distribution is larger than the chi-square value calculated for each variable (Boslaugh 2012). Furthermore, $\mathrm{p}$ value, which is smaller than the critical value, provides further evidence that gender, GPA, major do not correlate with the learning style. 


\begin{tabular}{|l|l|l|l|}
\hline Variables & Chi-square value & df & p \\
\hline Gender & 2.33 & 2 & 0.3119 \\
\hline GPA & 1.93 & 4 & 0.7486 \\
\hline Major & 0.89 & 4 & 0.926 \\
\hline
\end{tabular}

Table 5. Chi-square test result among three learning style groups and variables

Although there are no statistically significant differences between the variables and learning styles, an analysis of mean scores finds consistent results for the participants' GPA and their approach to learning (Table 6). The results revealed that the students engaged in deep learning achieve the highest results, whereas the students who approach the learning material strategically have the lowest academic performance. No correlation between gender or major and learning style has been found, although the findings report differences across the Deep, Strategic and Surface learning styles.

\begin{tabular}{|l|l|l|l|l|}
\hline & & Deep Approach & $\begin{array}{l}\text { Strategic } \\
\text { Approach }\end{array}$ & $\begin{array}{l}\text { Surface } \\
\text { Apathetic } \\
\text { Approach }\end{array}$ \\
\hline Gender & Male & 17.68 & 16.12 & 16.84 \\
\hline & Female & 17.16 & 15.48 & 16.52 \\
\hline GPA & High & 17.52 & 15.64 & 16.76 \\
\hline & Fair & 17.04 & 15.56 & 16.4 \\
\hline & Low & 16 & 14.52 & 16 \\
\hline Major & Med.-Tech & 17 & 15.64 & 16.68 \\
\hline & Tourism & 17.12 & 15.6 & 16.36 \\
\hline & English & 17.52 & 15.52 & 16.48 \\
\hline
\end{tabular}

Table 6. Mean scores of ASSIST scales by gender, GPA and major

Finally, Table 7 shows sample descriptive statistics for each subscale, including mean and standard deviation. The table also displays the comparison of the ASSIST scores obtained by the participants from studies carried out in Norway (Diseth 2001), Egypt (Gadelrab 2011), Portugal (Valadas, Goncalves and Faisca 2009), China and the UK (Sun and Richardson 2012). 


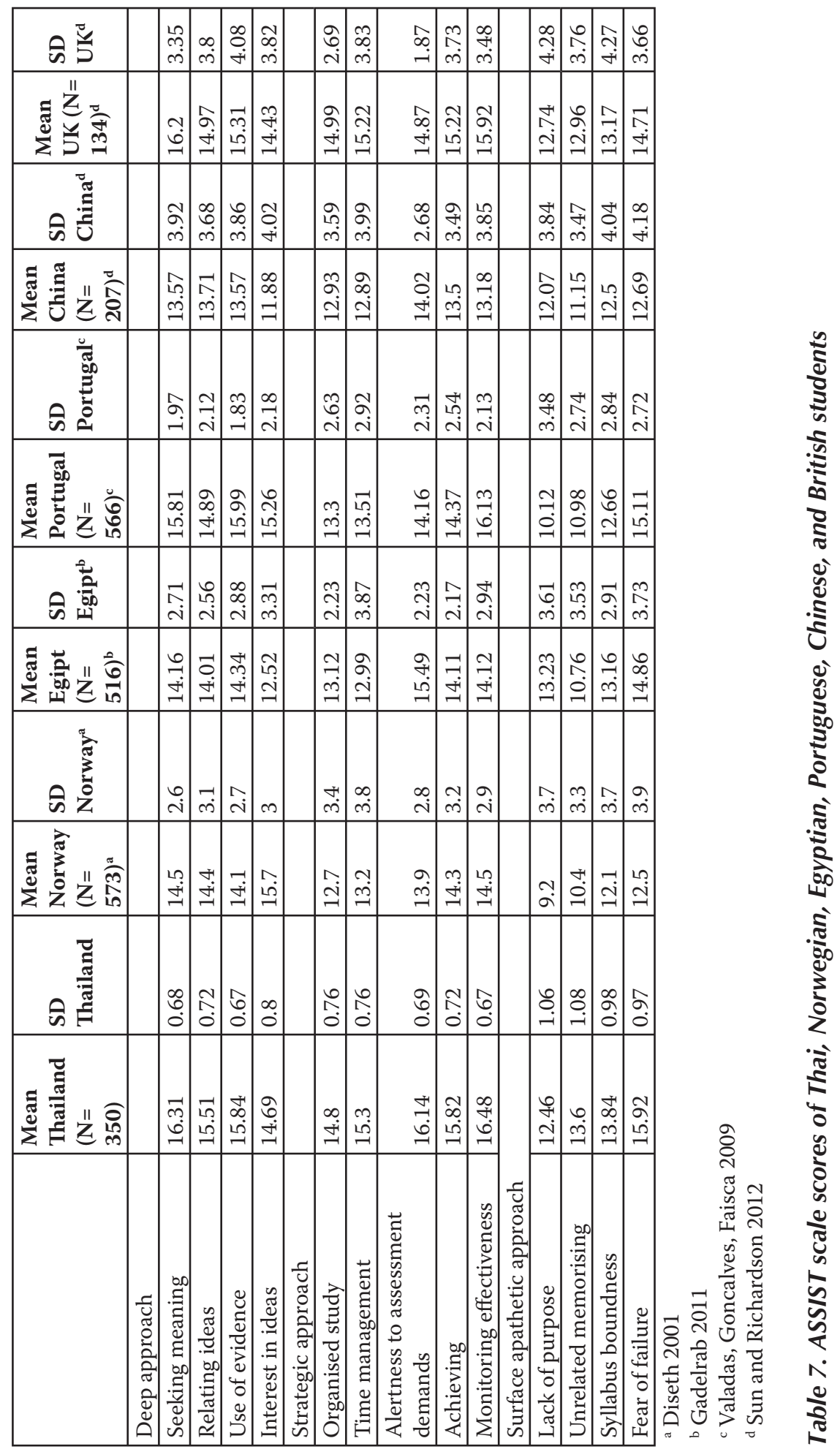


The investigation demonstrates evidence of internal reliability. When compared with other studies carried out in different countries, the results do not differ greatly. However, a close analysis of the results of the standard deviation shows a discrepancy between Thai students and other students coming from different countries. The data collected from Thai students is closely distributed; thus, scores give a small standard deviation, which proves that Thai students tend to give more homogenous answers.

\section{Discussion and conclusions}

The aim of the study was to analyse how students of various cultural backgrounds approach learning tasks, which is of utmost importance nowadays given that modern schools face the challenge of educating culturally diverse students. To this end, the Approaches and Study Skills Inventory for Students (ASSIST) was administered to a large group of college students from Thailand, whose approaches to studying were identified as deep, strategic, and surface apathetic. Next, the results were compared with the results obtained from students coming from different cultural backgrounds.

First, descriptive and inferential statistical analyses were conducted in order to draw conclusions about significant differences between dependent measures as a function of specific demographic variables including gender, GPA, and major. The results showed that although there are no statistically significant differences between gender, GPA and major with learning styles, an analysis of mean scores finds consistent results for the participants' GPA and their approach to learning. The results showed that the students scoring higher on the deep approach have the highest academic performance, whereas the students who approach the learning material strategically achieve the lowest learning outcomes. The results of the study were also compared with the results of similar studies carried out in different cultures. The Thai students did not differ significantly from their western peers (Norwegian, Egyptian, Portuguese and British); however, their results differed from the students from China, who generally scored lower on all three subscales of the ASSIST scores. 
A close investigation of components of approaches to studying shows high factor loadings: seeking meaning, use of evidence and relating ideas (deep approach components), alertness to assessment demands, achieving and monitoring effectiveness (strategic approach components) as well as fear of failure (surface apathetic approach component). This finding proves that students place high value on achievement and they frequently engage in studying because they are afraid of failure, which is the effect of the traditional educational system that emphasises the importance of testing and academic success. At the same time, the students engage in deep approach learning because they are curious, personally interested in the material and are eager to employ synthetic and inferential reasoning.

A large body of research shows that the disposition to understand for oneself, seeking meaning and relating ideas, which correlate with the deep approach to learning, can be effectively developed (Dogan, Atmaca and Aslan 2012; Entwistle and McCune 2009; Gadelrab 2011); therefore, teachers need to develop the deep approach to learning in learners, which is the most effective learning strategy. Classroom instruction should evolve around complex, authentic concepts that will engage students and help them understand learning can be applied to realworld problems. Authentic learning experience helps to develop a deep and lifelong approach to learning.

Finally, teachers need to be aware of differences among students, including differences resulting from the students' varied cultural backgrounds in order to minimise misunderstandings and difficulties in students' school-related activities. Due to increased migration, the structure of Polish classrooms is undergoing significant changes, as teachers increasingly often teach students coming not only from diverse social and ethnic groups but also from countries where instruction is delivered according to different principles. Thus, learners have varied schooling experience. However, the results of the study prove that students who come from culturally contrasting groups do not differ greatly in their choice of preferred learning style. Therefore, despite coming from different ethnic backgrounds, students study in a similar way. This finding sheds light on an important implication for Security Education: even though migration is often perceived as a challenge to societal security, migrant children can be well integrated into classrooms as they will achieve the goal of academic excellence adopting approaches and strategies to studying that are similar to host students. 


\section{References}

Apfelthaler G. et al, 2005. Cross-cultural learning styles in higher education. International Journal of Learning 22(5), 247-256.

Coffield, F., Moseley, D., Hall, E., and Ecclestone, K., 2004. Learning styles and pedagogy in post learning: a systematic and critical review. Cromwell Press: Trowbridge, Wiltshire.

Diseth, A., 2001. Validation of a Norwegian version of the Approaches and Study Skills Inventory for Students (ASSIST): Application of structural equation modelling. Scandinavian Journal of Educational Research 45(4), 381-394.

Dogan, C.D., Atmaca, S. and Aslan Yolcu, F., 2012. The correlation between learning approaches and assessment preferences of eighth-grade students. Elementary Education Online 11(1), 264-272.

Dunn, R. and Griggs, S., 1998. Learning styles: Link between teaching and learning. In R. Dunn and S. Griggs (Eds), 1998. Learning styles and the nursing profession. Jones \& Barlett Learning: New York, 11-23.

Dunn, R. and Dunn, K., 1993. Learning Styles/Teaching Styles: Should They•.. Can They... Be Matched? Educational Leadership, 238-244.

Entwistle, N.J., 2000. Promoting deep learning through teaching and assessment: conceptual frameworks and educational contexts. [15 March 2017] http://www.leeds. ac.uk/educol/documents/00003220.htm

Entwistle, N.J. and McCune, V., 2009. The disposition to understand for oneself at university and beyond: Learning processes, the will to learn, and sensitivity to context. In L.F. Zhang and R.J. Sternberg (eds), 2009. Perspectives on the nature of intellectual styles. Springer: New York, 29-62.

Entwistle, N.J. and Ramsden, P., 1982. Understanding student learning. Croom Helm: London.

Entwistle, N. J., Tait, H. and McCune, V., 2000. Patterns of response to an approaches to studying inventory across contrasting groups and contexts. European Journal of the Psychology of Education 15, 33-48.

Evans, C. and Waring, M., 2009. The place of cognitive style in pedagogy: Realizing potential in practice. In L. F. Zhang and Sternberg, R. J. (Eds.), 2009. Perspectives on the nature of intellectual styles. Springer Publishing Company: New York, 169-208.

Gadelrab, H.F., 2011. Factorial structure and predictive validity of Approaches and Study Skills Inventory for Students (ASSIST) in Egypt: A confirmatory factor analysis approach. Electronic Journal of Research in Educational Psychology 9(3), 1197-1218.

Hof, M., 2012. Questionnaire evaluation with factor analysis and Cronbach's Alpha. [15 March 2017] http://www.let.rug.nl/nerbonne/teach/rema-stats-meth-seminar/ student-papers/MHof-QuestionnaireEvaluation-2012-CronbachFactAnalysis.pdf. 
Holtbrügge, D., Mohr, A.T., 2010. Cultural Determinants of Learning Style Preferences. Academy of Management, Learning and Education, 9(4), 622-637.

Lauria, J., 2010. Differentiation through learning style responsive strategies. Kappa Delta Pi Record, 24-29.

Marton, F. and Saljo, R., 1976. On qualitative differences in learning. I. Outcome and process. British Journal of Educational Psychology 46, 4-11.

Minotti, J.L., 2005. Effects of learning-style-based homework prescriptions on the achievement and attitudes of middle school students. NaSSP Bulletin 89(642), 67-89.

Pieczywok, A., 2012. Edukacja dla bezpieczeństwa wobec zagrożeń $i$ wyzwań i zagrożeń wspótczesności. Wydawnictwo AON, Warsaw.

Pritchard, A., 2014. Ways of Learning: Learning Theories and Learning Styles in the Classroom. Routledge: New York.

Rochford, R.A., 2004. Improving academic performance and retention among remedial students. The Community College Enterprise 10(2), 23-36.

Sun, H., and Richardson, J.T.E., 2012. Perceptions of quality and approaches to studying in higher education: A comparative study of Chinese and British postgraduate students at six British business schools. Higher Education 63, 299-316.

Tait, H., Entwistle, N.J. and McCune, V., 2000. ASSIST: A Reconceptualizaton of the Approaches to Studying Inventory. In C. Rust (ed.), 2000. Improving Students as Learners. Oxford Brookes University, the Oxford Center for Staff and Learning Development: Oxford, 262-271.

Urych, I., 2016. Military class in Poland - experiences and perspectives. Security and Defence Quarterly 2(11), 112-134.

Urych, I., 2018. Edukacja dla bezpieczeństwa. Wspótczesne kategorie. Wydawnictwo Akademii Sztuki Wojennej, Warsaw.

Valadas, S.C.A.T.S., Goncalves, F.R. and Faisca, L.M., 2009. Approaches to studying in higher education Portuguese students: A Portuguese version of the approaches and study skills inventory for students. Higher Education 59, 259-275.

Wang, K.H., Wang, T.H., Wang, W.L. and Huang, S.C., 2006. Learning styles and formative assessment strategy: enhancing student achievement in Web - based learning. Journal of Computer Assisted Learning 22(3), 207-217. 